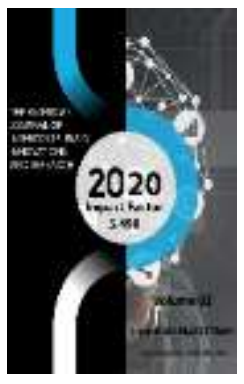

Journal Website: http://usajournalshub.c om/index,php/tajiir

Copyright: Original content from this work may be used under the terms of the creative commons attributes 4.0 licence.

\section{Alternative Ways To Study The Impact Of Ground Vibrations From Explosions On The Stability Of Buildings And Structures}

\author{
Rasul Jumabayevich Tojiyev \\ Doctor Of Technical Sciences, Professor, Ferghana Polytechnic Institute, Ferghana, \\ Uzbekistan \\ Elmurad Muhammadyakubovich Yunusaliev \\ PhD, Associate Professor, Ferghana Polytechnic Institute, Ferghana, Uzbekistan \\ Ibrohim Numanovich Abdullayev \\ PhD, Associate Professor, Ferghana Polytechnic Institute, Ferghana, Uzbekistan
}

\title{
ABSTRACT
}

The existing basic methods of studying the propagation of seismic-explosive waves in various mininggeological and morphological conditions to assess the impact of explosions on buildings and structures are briefly outlined. The results of studying the effect of the influence of the terrain on seismic vibrations during the passage of seismic explosive waves in them are presented. The issues of organizing experiments in full-scale field conditions, the time of which entirely depends on the time of drilling and blasting operations, are highlighted, which significantly slows down the stages of design, construction and operation of buildings and structures. Along with various explosions, as well as existing expensive installations and stands that create artificial vibrations for buildings and structures, it is offered detonation method for creating vibrations in the ground, both in design and construction, so and in the operation of buildings and structures. The detonation method proposed by the authors for creating artificial ground vibrations using a gas detonation unit makes it possible to simplify and accelerate the experiments and reduces labour and material costs.

\section{KEYWORDS}

Kt-kilotons, mt-megatonne, ground vibrations, drilling and blasting operations, seismic waves, blast waves, seismic resistance of buildings and structures, detonation, detonation explosion, gas detonation generator.

\section{INTRODUCTION}

The energy of explosions is widely used in practice, in mining for crushing rocks, prospecting for minerals, developing research edits, mining ore, in construction, in the construction of hydraulic engineering, transport structures and roads, compaction of 
the foundations of buildings, for military purposes, as a source of elastic waves used to study the structure of the Earth, and finally. for the development of the science of seismology and seismic resistance, in the development of methods of seismic construction.

Each explosion produced underground, in water, or the atmosphere excites certain vibrations in the earth. Therefore, explosions, as well as earthquakes, should be considered as seismic events [1].

Every year, hundreds of thousands of natural earthquakes are registered on the globe. Of these, about 1,000 earthquakes correspond to seismic signals for explosions with a power of more than $10 \mathrm{kt}$, and about 10,000 earthquakes correspond to explosions with an equivalent energy of about $1 \mathrm{kt}$. According to [2], the seismic energy released per year by all earthquakes in the form of elastic waves is approximately $10^{25} \mathrm{erg}$, which in terms of the explosion energy is about $10^{3} \mathrm{MT}$.

Seismic events associated with blasting operations are quite comparable to natural earthquakes both in terms of the intensity of vibrations and the number of events per year during industrial explosions. Indeed, since 1961. every year, 30 to 60 nuclear explosions are carried out with a capacity of 1 to 150 kt each, and by 1975 , the power of individual explosions sometimes reached several megatons. The vibrations of the earth caused by such explosions are equivalent in their intensity to those caused by earthquakes of magnitude $M=3 \div 7$. The total energy released during nuclear explosions per year is characterized by a value of about 10 MT.

A large volume of blasting operations is also carried out in mining and construction with the use of chemical explosives (CE). At present, about $10^{7}$ tons of explosives are consumed throughout the world throughout the year. Such a mass sacrificial BB corresponds to the order of magnitude is the total energy of nuclear explosions for the year. The main volume of blasting operations in the industry is carried out by borehole charges, which are detonated in groups with a total mass of explosives in the tens and hundreds of tons. Consequently, for the year on earth is happening over hundreds of thousands of seismic events associated with the industrial explosion, equivalent to $E$ earthquakes with a magnitude of $M=1 \div 3$.

It also follows from the given scales of blasting operations that the total energy of all underground explosions per year, both nuclear and chemical, is about $10^{23}$ ergs. The bulk of the energy of these explosions is spent on irreversible deformations of the rock around the charge (displacement, destruction, heating) and only about $1 \%$ is emitted in the form of seismic energy. Consequently, the total contribution of blasting operations to seismic events is characterized by a value of the order of $10^{21} \mathrm{erg}$ of elastic energy, which is four orders of magnitude less than the seismic energy of earth vibrations during earthquakes.

Studies of ground and structure vibrations during explosions occupy a prominent place in seismology and earthquake-resistant construction. Seismic effects must be taken into account when ensuring the safety of drilling and blasting operations and large explosions in construction. In many cases, it is the seismic effect that limits the magnitude of the maximum charge of explosives, which significantly affects the final result.

\section{MATERIALS AND METHODS}

Seismic ground vibrations can provide control over the conduct of underground nuclear tests. As a result of the development of research in these areas, explosion seismology has emerged as a scientific field. Historically, there are three stages of development in explosion seismology: 
- the first one refers to the 30-the 40 s of the last century, when, along with the development of explosive technology in construction and mining, the question arose of studying the destructive effect of seismic explosive waves. The solution to this problem is associated with the works of academician M.A.Sadovsky [3], in which, based on the analysis of experimental data on the destruction of buildings and structures under the influence of vibrations during industrial explosions, it was found that the intensity of destruction is determined by the value of the mass velocity of soil movement in a seismic wave;

- the second stage in the development of seismology of explosions dates back to the 60-70 years when the problem arose of ensuring seismic safety during underground nuclear explosions, including when used for peaceful purposes. To resolve this issue for abroad a large body of instrumental observations, particularly in the area near the explosion, where seismic waves are destructive nature [4]. As a result, the main regularities of the propagation of seismic waves at various distances from the explosion site were established. A significant achievement of this stage was the development of new methods for predicting the parameters of the seismic action of powerful explosions, which also included a statistical approach to assessing the degree of damage to various types of structures;

- the third stage in the development of seismology of explosions began in the late $70 \mathrm{~s}$ and is associated with the emerging need to control the conduct of underground nuclear tests. It was necessary to convincingly prove the technical possibilities of such control by seismological means and to increase its sensitivity. Control problem involves two main tasks: detecting signals from the explosion and their identification I with earthquake s. In order to solve this problem, numerous seismic stations were deployed, forming international seismological networks. The stations were equipped with short-period and longperiod seismographs, which were located over large areas in groups in the form of triangles, crosses, various kinds of polyhedrons to improve the ratio of the useful signal to natural seismic noise and to establish the coordinates of the vibration source. At present, it is generally accepted that it is possible to register and recognize a seismic signal from an underground nuclear explosion with a power of less than $1 \mathrm{kt}$. The equipping of seismological networks with new equipment and their automation continues intensively. A unified international seismic control network is being developed. Solving the problem of detecting nuclear tests by seismic means required the development of a unified approach to the study of the seismic action of explosions and earthquakes, which led to the mutual penetration of the methodologies for studying these seismic events and significantly brought the seismology and seismic explosions closer together.

It should be noted that from the point of view of studies of the seismic safety of buildings and structures during industrial explosions, two different directions can be distinguished:

- The first direction refers to flat territories;

- The second to the mountainous regions.

For lowland areas, when determining the intensity of seismic vibrations on various soils, records of kinematic parameters of ground vibrations are used and their spectral characteristics are constructed taking into account the increment of the ballast when passing from one "ground conditions" to another. In this case, calculations are made according to different formulas based on the 
use of displacements, velocities, accelerations, deformations, acoustic stiffness and vibration damping. This direction has been widely developed based on the results of instrumental observations and theoretical research.

For mountainous regions, the task is reduced to studying the influence of the terrain on the intensity of seismic vibrations on the earth's surface, taking into account the geometric and physical parameters of the upper layers. The main task of this line of research is to identify the effects of the influence of various forms of terrain on the intensity of vibrations during the passage of a seismic wave. Taking this effect into account when assessing the change in scoring is of great interest for the region while ensuring the seismic resistance of objects since the facts show a significant effect of the terrain on the change in the intensity of seismic vibrations.

The study of the consequences of several earthquakes showed a significant effect of complex geological conditions and terrain on the intensity of seismic vibrations on the earth's surface. Taking into account the decisive role of the soil found in ensuring the seismic stability of structures, research is also underway to study the regularities of deformation of multilayer soil media under dynamic influences, taking into account the nonlinear properties of the medium [5].

Blasting operations are often performed in areas near industrial and cultural facilities. In this regard, there is a need to study the laws of propagation of seismic waves in ground media (rocks) depending on their physical and mechanical properties and conditions of the area of drilling and blasting operations, the Geology and terrain of the wave propagation route, the intensity of ground vibrations and the impact of seismic waves on objects at different distances from the explosion site. The safety of buildings and structures largely depends on the nature and intensity of wave phenomena during underground explosions, as well as on the type and design features of structures. For the safety of buildings and structures, it is of great importance to correctly determine the maximum permissible ground vibration rates, earthquake-safe distances and charge power. Inaccurate determination of these parameters can cause damage to buildings and structures. The seismic safety of buildings and structures during underground explosions depends both on the seismic stability of the above objects and on the intensity of ground vibrations[6].

An important condition here is to determine the intensity of the impact of industrial explosions and ensure the seismic safety of buildings and structures in difficult mining and geological conditions, the solution of energy problems without significant damage to the ecological situation in the region.

In the present research, the Central idea based on the principles of gas dynamics is the use of a detonation wave, as it is more often called an explosion, as a "tools" of force action.

Development of the theory and experiment of detonation of gas mixtures needed in the first, for the correct selection of theoretical tools in the appointment of key project research parameters, and secondly, to study the composition of research, namely, to be excluded from work issues already wellstudied. It should be noted that detonation is the process of propagation of a flame front in gas and condensed mixtures of fuel and oxidizer, consisting of a shock wave, a zone of chemical reactions and a zone of expansion of products of chemical reactions. This type of combustion, in contrast to the so-called normal combustion, is characterized by high speeds.

The detonation of gas mixtures of conventional fuels (gasoline, gas) with air gives an impulse with the following parameters: pressure in the shock wave 35 ATM.; - flow rate of detonation products $800 \mathrm{~m} / \mathrm{sec}$. ; - the movement of the detonation wave through 
the channel-at a speed (as shown above) of the order of $1600-1800 \mathrm{~m} / \mathrm{sec}$ - for fuels and $6000-$ $7000 \mathrm{~m} / \mathrm{sec}$. - for TNT.

The beginning of the systematic scientific study of detonation was laid by scientists Berthelot and Viel [7], Painter and Le Chatelier [8]. To date, the main provisions of the detonation theory have been developed in subsequent works.

The qualitative principle of the process description is that a pipe closed at one end and filled with a gaseous mixture of fuel and oxidizer. A detonation wave occurs at the closed end and propagates to the open end of the pipe.

In essence, the process from the moment of the appearance of a detonation wave (DW) at the closed end of the tube to the complete outflow of detonation products (PD) from the tube is divided into several periods differing from each other. Let's consider these periods in more detail:

- The period of passage of the DW from the closed to the open end of the pipe. During this period, the initial mixture is either at rest and does not flow out of the pipe, or it flows out with some initial velocity $I_{0}$., Etc. The pressure meters, density $\mathrm{W}$ and temperature of the feed mixture - $\mathrm{P}_{0}, \mathrm{p}_{\mathrm{o}} \mathrm{T}$ $\circ$. Behind the detonation wave, there is a certain zone of motion of the DP following the DW. Closer to the closed end of the pipe, there is a rest zone of the PD, in which the PD does not move. Parameters in the rest zone $P_{n}, f_{1}, T_{p}, I_{p}=O$;

- The period of the PD outflow from the pipe from the moment the DW passes the open end to the moment the first rarefaction wave arrives at the closed end of the pipe During this period, the pressure on the closed end of the pipe does not change. (i.e. $\mathrm{P}_{\mathrm{n}}=$ const);

- The period of critical outflow of PD from the pipe from the moment the first rarefaction wave is reflected from the closed end of the pipe and until the moment when the outflow velocity from the pipe becomes less than critical. During this period, the movement of the PD from the closed end of the pipe occurs at a critical speed and disturbances from the open end cannot pass against the flow. The parameters at the closed end $\mathrm{P}_{3}, \mathrm{f}_{3}, \mathrm{~T}_{3}, \mathrm{~h}$ 3 , during this period are variable;

- The period of subcritical expiration of the PD from the pipe from the moment when And $\angle C$ ( $C$ is the speed of sound) to the full expiration. This period is divided into several stages, during which the pressure in the pipe is not only equalized with the pressure in the environment but also a rarefaction and a return flow of air from the atmosphere to the pipe is formed. The process is periodic and decaying.

In fig. 1 shows the distribution of parameters according to the hydrodynamic theory. An arbitrary position of the shock wave along the length of the pipe and at the moment of its arrival at the open end is taken. Numerical values are given for mixtures of air with hydrocarbon fuels.

The initial mixture with the parameters Po, $p \circ$, To, and IO is compressed by a shock wave (SW) at a small length (almost instantly). According to L. B. Zeldovich [9], " the width of the front of a strong shock wave does not exceed the length of one free path" of the molecule. 


\section{Detonation wave}

\section{Figure: I. Scheme of parameter distribution according to hydrodynamic theory}

Let us consider the phenomenon of an explosion of a warm-air mixture in a pipe, in which one end is completely closed and the other is completely open

Imagine that the pipe is filled with a mixture of gasoline vapours and air (Fig. 2 a). The ratio of gasoline and air is such that the oxygen contained in the air is sufficient for the oxidation of gasoline (the so-called stoichiometric ratio). With this ratio, or little different from it, a conventional carburettor internal combustion engine works. The pressure of the mixture $\mathrm{P}$ is equal to atmospheric (Po), the temperature $t$ is assumed to be $\mathrm{l}=+20^{\circ} \mathrm{C}$, the mixture is at rest (the speed "IF*" is zero). These parameters are shown in the graph in figure $2 a$.

Let's assume that at the closed end of the pipe, we set the mixture on fire quite intensively, for example, with a strong electric discharge. You can choose the discharge power so that explosive combustions (detonation) will immediately begin. For figure $-1 B$ shows the state of the gas parameters in the pipe, at the moment when the explosive combustion spread from the closed end of the pipe to a distance of 1.Gorenje In the section of pipe where the combustion has not yet reached (Fig. $2 \mathrm{~b}$ is the section $\mathrm{L}-1$ ) the pressure Po, temperature $t$, and velocity of The $I O$ mixture are equal to the initial values (as in Fig. 2a). There are no changes in this part. In the crosssection of the pipe, at a distance from the closed-end equal to 1 , there is a shock wave - a very narrow zone, on the order of several $\mathrm{mm}$, in which the mixture is compressed to a pressure of $R_{u v}=35$ ATA. From this compression, the mixture is heated to approximately a temperature of tyB $=1500 \mathrm{C}$. 


\section{a)}

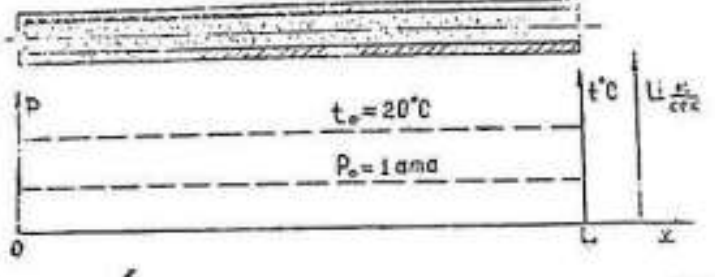

8)

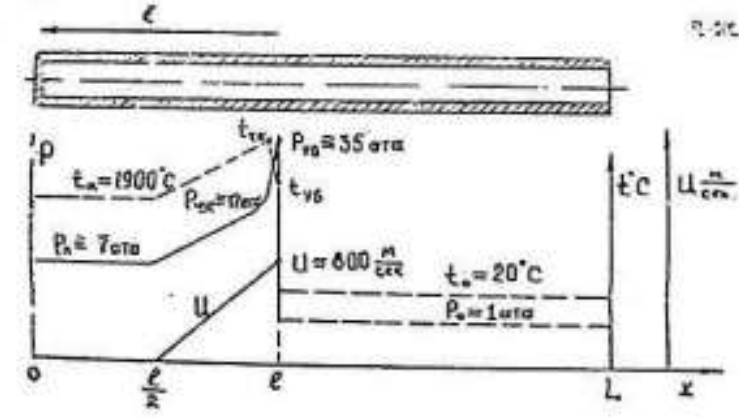

s)

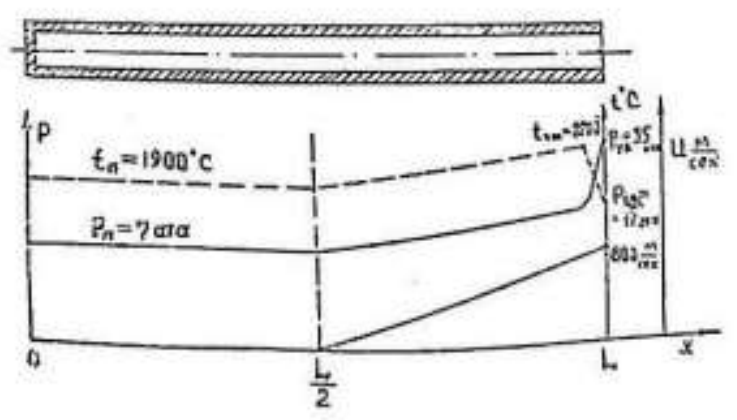

Figure: 2. Scheme of filling the pipe with a gaseous mixture.

Naturally, from this temperature, the mixture ignites and after a short period of time completely burns, the temperature of the combustion products becomes equal to $t h$. W. $=2000^{\circ} \mathrm{C}$, the pressure $\mathrm{Ph} . \mathrm{W}=17 \mathrm{ATA}$. "Gorenje Gorenje" index denotes a special zone where the combustion of the mixture ends: it is taken from the initial letters of the surnames of Professor Chapman and Jouguet - researchers of detonation combustion.

Behind the shock wave from the side of the closed end of the pipe, the combustion products no longer rest as a fresh mixture but move towards the open end of the pipe at a speed of about $\mathrm{U}=800 \mathrm{~m} / \mathrm{s}$.

On the section of the pipe from $C$ to 1 , there is a change in $\mathrm{P}, \mathrm{t}$, and approximately as shown in
Fig. $2 b$ in the cross-section of the pipe at a distance from the closed end-Ug, the so-called rest zone is established. The rate of combustion products here is zero, the pressure is on the order of $\mathrm{RP}=7 \mathrm{ATA}$, the temperature is just below $t h$. $f$. and is equal to $t n=1900^{\circ} \mathrm{C}$.

The shock wave moves along the pipe at a speed of $D=1800 \mathrm{~m} / \mathrm{s}$ towards the open end. In theory, this velocity is called the detonation velocity and is denoted by the letter $D$. When the shock wave approaches the open end of the pipe, it "burns" the entire mixture and the parameters shown in Fig. 1 will be established in the pipe. $1 \mathrm{C}$, namely: pressure $\mathrm{Pp}=7 \mathrm{~atm}$ at a length $L / 2$ and rising to the open end to $P p=$ 17 ata; the speed of movement of combustion products, increasing in the section $L / 2+L$ up to 
$800 \mathrm{~m} / \mathrm{s}$ - temperature up to t h.zh. $=1900{ }^{\circ} \mathrm{C}$; narrow compression zone $\mathrm{PB}=35$ ata. The time during which the entire mixture burns out is equal to $L / D$ (if the pipe is $1 \mathrm{~m}$ long, the time is $1 / 1800 \mathrm{~s}$, if $3 \mathrm{~m}$; the time is $3 / 1800=1 / 600 \mathrm{~s}$ ). As you can see, combustion occurs almost instantly and a significant amount of energy is generated in the volume of the pipe in the form of potential (pressure of combustion products), kinetic (movement of combustion products), kinetic (movement of products into combustion at a speed of up to $800 \mathrm{~m} / \mathrm{s}$ ) and heat (hot products combustion). Note that no catastrophically high forces arise in this explosion and it is quite possible to cope with it, it can be withstood by an ordinary water pipe. If now we can organize explosions, following one after another, then we get an explosive-type energy generator that works as long as we want, like a conventional internal combustion engine. The amount of energy released in every single explosion is regulated by the amount of mixture in the pipe. For a more visual representation of such explosive tubes as sources of energy, let us compare them with internal combustion engines. A vehicle with a four-stroke engine, the working volume of which eight cylinders equal to $6 n$. filled with the fuel-air mixture, at engine speed $180.0 \mathrm{rpm}$ (30 rpm) uses litres of mixture per second. This amount of the mixture can be burned in 9 blast tubes operating at a frequency of 5 times/sec each, with a diameter of $25 \mathrm{~mm}$ and a length of $2 \mathrm{~m}$ [10].

The energy that is released during the complete combustion of the same amount of fuel-air mixture in both cases is the same because it was complete. Thus, there is an 8 cylinder car engine and nine explosive pipes each with a diameter of $25 \mathrm{~mm}$. and a length of $2 \mathrm{~m}$. at a response frequency of 5 times/sec each, the same amount of energy is released.

Figuratively speaking, 20\% of the energy released by the engine is concentrated in a relatively small explosive tube in the form of potential (pressure), kinetic (flow movement) and thermal (temperature) energies, which can be used for various purposes, including to create oscillations soil. The ongoing experimental research is aimed at studying the nature of the above phenomenon in order to create artificial ground vibrations using a gas detonation unit. In this regard, experimental studies are being carried out to select the power of this unit, the optimal type, composition and amount of fuel for its effective use.

\section{CONCLUSION}

When achieving the goal and solving the intended tasks, the study of the influence of ground vibrations from detonation methods of impact, instead of explosive methods, makes it possible to significantly accelerate the technology and organization of such work, reduce the cost of labour, time and material resources for the development of ground vibrations. The result will be an acceleration of the processes for studying the influence of ground vibrations on the seismic stability of buildings and structures during their design, construction and operation, and this is always relevant in conditions of high seismic activity.

\section{REFERENCES}

1. Sadovsky, M.A., Daragan, S.K., Dolgopolov, D.V., \& Kondorskaya, N.V. (1987). On the method for determining the energy released during an earthquake. In Papers of the Academy of Sciences, (Vol. 293, No. 3, pp. 575-578). The Russian Academy of Sciences.

2. Rodin, G., \& Kogan, S. Ya. (1974). Seismology of nuclear explosions. World.

3. Sadovskii, M. A., \& Kostyuchenko, V. N. (1974, January). On the seismic effect of 
underground explosions. In Dokl. Akad. Nauk SSSR, (Vol. 215).

4. V.I. Rodionov On the mechanism of excitation of low-frequency body seismic waves in an underground explosion., J. Prikl. fur. tech. Physics, 1981, No. five.

5. Sagdiev H., Yunusaliev E. M. (2004). Investigation of the impact of seismic waves on structures and ground environments in mountainous areas. Tashkent, 280-283.

6. Sagdiev H., Yunusaliev E. (2006). Assessment of the seismic effect of industrial explosions produced in complex mining and geological conditions. Uzbek journal "Problems of mechanics", No.3, pp. 29-34.
7. Berthelot V.T'cille 7compl rend 95, 18 (1\&81), Acad, Sei, Paris.

8. Mallard L., Chatelier H., (1881). Comp (rend./lead Sei., Paris, 95, 145.

9. Zel'dovich, Ya.B., \& Kompaneets, A.S. (1955). Detonation theory. Approved by the USSR Ministry of Higher Education as a textbook for higher educational institutions. State publishing house of technical and theoretical literature.

10. Tojiev R. Z., Sadullaev H. M., Isomiddinov A. S. (2017). Application of gas-dynamic principle in agricultural technology. Ferghana. 